\title{
Experimental study of ISHTAR thermostatic irradiation device for the MARIA research reactor
}

\author{
Maciej Lipka*, Anna Talarowska, Grzegorz Wojtania, Marek Migdal \\ National Centre for Nuclear Research, Poland \\ *corresponding author: Maciej.lipka@ncbj.gov.pl
}

\begin{abstract}
Materials and core components for the next generation power reactors technologies require testing that can be performed in existing research reactors. Such experiments employ devices dedicated to reflect the relevant thermal and neutron parameters simulating conditions present in, for example, but not limited to, HTGR reactors. A novel thermostatic irradiation device named ISHTAR (Irradiation System for High-Temperature Reactors) has been designed and constructed in the MARIA research reactor. Its mission is to enable irradiation of samples in controlled, homogeneous temperature field reaching $1000^{\circ} \mathrm{C}$ and inert gas atmosphere. The high temperature is achieved by a combination of electric and gamma heating, together with carefully designed thermal insulation. Additionally, samples holder made of graphite with high thermal conductivity enables the temperature homogenization in all directions. Device will be placed inside the Beryllium matrix of MARIA core and cooled with forced circulation of water from the reactor pool loop. This paper presents the outcome of experiments conducted with the rig prototype in external hydraulic mock-up of the MARIA reactor irradiation channel. The results have proved that the desired conditions for irradiation of the samples were achieved and their comparison against computational data has shown the adequacy of the design process. Finally, the loss of flow scenario was tested in protected and unprotected conditions (meaning with and without the safety system based on temperature feedback), proving the operational safety of the ISHTAR design. Experimental results will be used in the future to validate the numerical models (two and three dimensional) of the irradiation rig, providing an improved understanding of free convection and radiation phenomena modeling.
\end{abstract}

Keywords - Research reactor, materials testing, Irradiation, High-temperature Reactor, thermostatic device, MARIA, HTGR

\section{INTRODUCTION}

MARIA is a channels-in-pool type, water-cooled research reactor. It has a nominal power of $30 \mathrm{MWth}$ with a core containing 20+ individually cooled fuel elements located in pressure tubes. Beryllium blocks and light water provide neutrons moderation. The reactor core is surrounded by the graphite reflector [1]. MARIA's core is highly flexible - fuel channels and beryllium (moderator) blocks might be freely shuffled between the reactor cycles to meet the requirements of the broad scope of irradiation programmes and experimental studies for each operation cycle. Irradiation positions with neutron flux and spectrum optimized for the thermostatic devices programme are presented in Figure 1.

As the High-Temperature Reactors (HTGR or HTR) seem to be considered by the Polish government as a meaningful branch of scientific studies in the field of nuclear energy [2][3] (however separate from the Polish Nuclear Power Programme [4] ), the need for the development of thermostatic rig that will enable irradiations in the HTGR conditions emerged. As a result, a state-funded research programme "Gospostrateg-HTR" was initiated. One of its tasks was designing, building, and testing the irradiation rig in the research reactor core. The rig enables graphite samples irradiation in thermal conditions as close as possible to HTGR operating conditions, namely $1000^{\circ} \mathrm{C}$ and helium gas atmosphere. The initial rig design was carefully optimized to minimize heat flux in axial direction and homogenize the temperature field within the holder filled with materials samples. The optimization process, which leads to the final axial insulation arrangement, required tight cooperation between analysts and design engineers. Test of the prototype was performed to measure thermal and hydraulic conditions in the external mock-up of the vertical irradiation channel of the MARIA reactor - coolant flow correlated with the known pressure drop. When the hydraulic conditions were known (and derived from them - heat transfer coefficient), thermal measurements became possible: the temperature at various points inside and outside the rig was measured to map the temperatures and compare them with calculation results of the measurements to prove the adequacy of the design. 


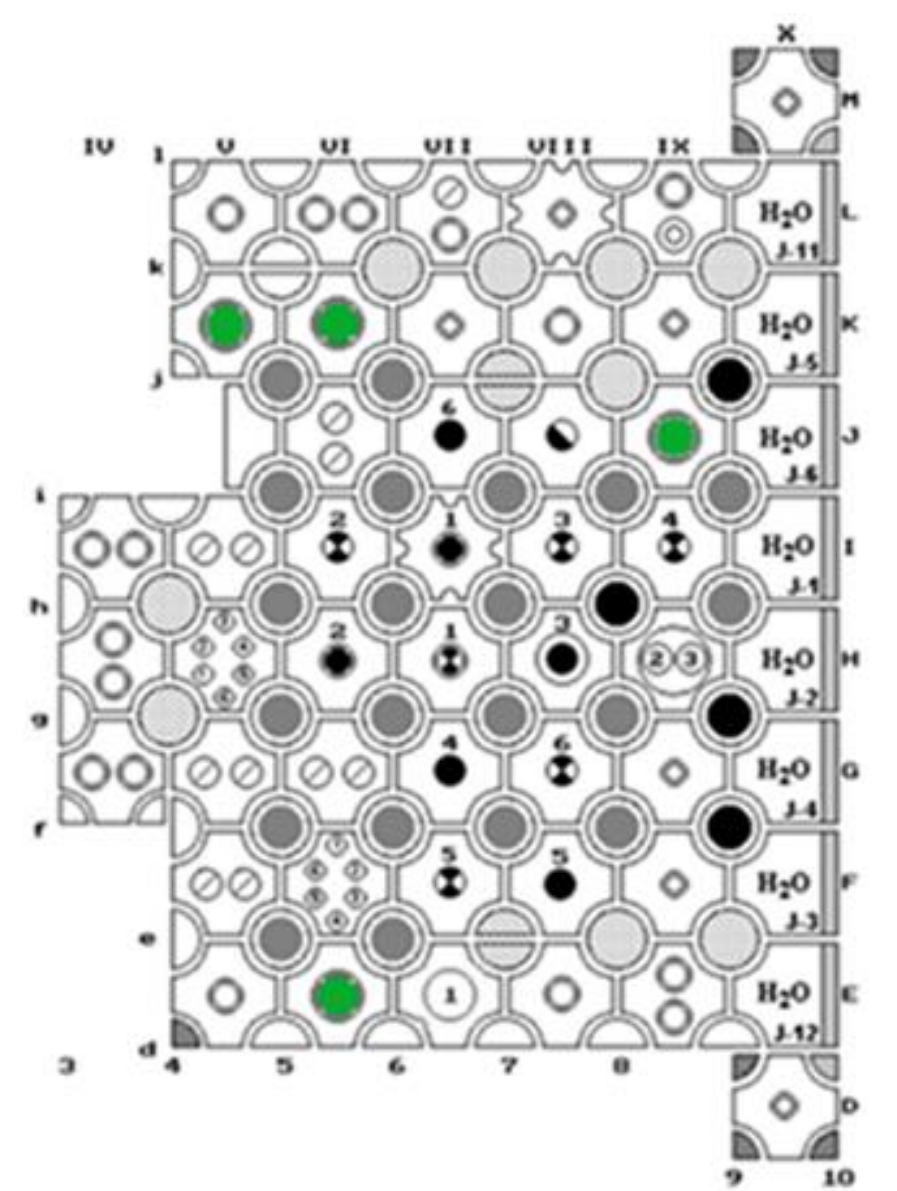

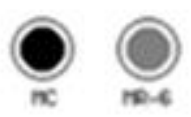

Fuel elements

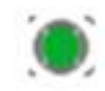

Irradiation positions for thermostatic capsule

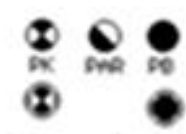

Control rods
Fig. 1: Irradiation positions in MARIA reactor core

\section{ISHTAR DESIGN}

The ISHTAR (Irradiation System for High-Temperature Reactors) thermostatic irradiation rig ensure homogenous temperature both by nuclear and electrical heating during incore irradiation. The prototype used for the mock-up tests has an elevated electrical heating to fill in the nuclear heating during out of the core safety testing procedures.

The main feature of the rig is the homogeneous irradiation temperature of $40 \mathrm{~cm}$ specimen's holder length which is quite impressive comparing to the $1 \mathrm{~m}$ of active reactor core height. The homogenous temperature of $1000^{\circ} \mathrm{C}$ was achieved by helium gas insulation layer. The outer diameter of the rig $\mathrm{d}=48.3 \mathrm{~mm}$ can be easily fitted to the vertical channel which internal diameter equals $54 \mathrm{~mm}$. The rig is cooled by the forced convection of water in reactor pool. The main goal of ISHTAR thermostatic device was to demonstrate the possibility of graphite specimen irradiation in high temperatures. The thermostatic device irradiates four graphite specimen, each $100 \mathrm{~mm}$ long. Samples from this irradiation campaign are intended for the pull tests. The samples are fitted with six thermocouples as part of the temperature monitoring inside the thermostatic device. The specimen is implemented inside the rig's tray, with cylindrical loading space of diameter $28 \mathrm{~mm}$ and $400 \mathrm{~mm}$ long. The tray encapsulating the loading space is wrapped in 7 high-temperature heaters. The heaters are placed in spiral grooves and interlaced at the bottom, allowing both cold ends of each heater directly upwards. The heater interfaces stainless steel sleeve tube's outer diameter allows maintaining $3.15 \mathrm{~mm}$ isolating gap between thermostatic device tray and thermostatic device outer tube. The gap is filled with helium with a pressure of 1.5 bar, providing isolation necessary to reach a temperature of $1000^{\circ} \mathrm{C}$ inside the tray. Thermal expansion shrinks the gap to about $2.85 \mathrm{~mm}$, which was taken into account in the calculations. The upper and lower ends of the tray in the sleeve are additionally isolated by rings manufactured from Zirconium-Yttrium ceramic with low thermal conductivity of $2 \mathrm{Wm}^{-1} \mathrm{~K}^{-1}$ combined with the helium volumes. The whole assembly is locked within the stainless steel (AISI316) cylinder, providing structural rigidity to the assembly. The construction is presented in the Figure 2.

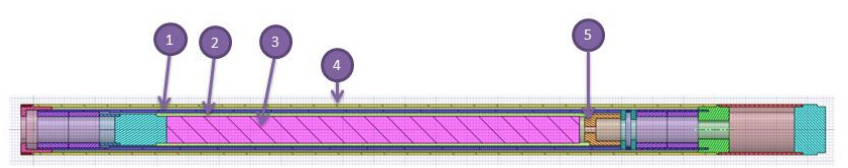

Fig. 2: Geometrical model of the in-core part of the thermostatic device.

1 - inner shell, 2 - electrical heater, 3 - samples with holder, 4 - outer shell, 5 - "crown" (lower insulation).

\section{EXPERIMENTAL SETUP}

Due to several major uncertainities (such as coolant velocity in the channel) as well as due to the complex geometry of the heater it is difficult to simulate the temperature field numerically within the rig. Therefore, it has been decided to perform an additional experimental investigation in order to determine cooling parameters and verify technical solutions by performing out-of-core experiments in reactor channel mockup. It allowed to adequately test selected insulators, connectors, etc. A purpose-designed mock-up of the irradiation channel with full simulation of its cooling capacity has been therefore constructed. The mock-up called FLOW-30 is presented in Figure 3. The transparent structure of the mock-up made out of the plexiglass tubes enables observation of the flow type: laminar or turbulent after the addition of the reagent to water, also boiling and its regimes can be investigated in this manner if they occur. 


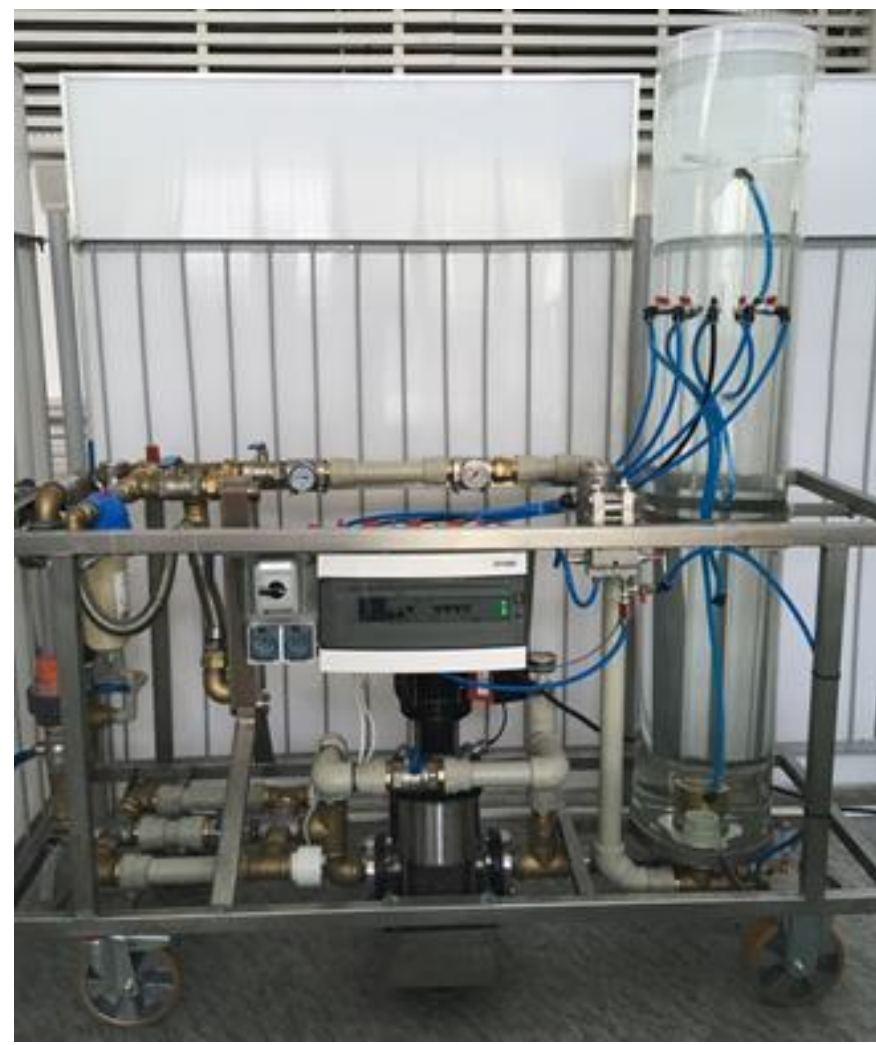

Fig. 3: FLOW-30 Experimental hydraulic stand

The experimental stand FLOW-30 allows performing thermal and hydraulic measurements in 1:1 scale, both in heat transfer and geometrical terms. The stand is equipped with water temperature and flow rate measurement and control systems. A number of pressure sensors allow to determine pressure drop. It is possible to correlate the flow rate with pressure drop and water gap thickness. The heat transfer coefficient $\left[\mathrm{W} \cdot \mathrm{m}^{-2} \cdot \mathrm{K}^{-1}\right]$ can be therefore determined.

Parameters of stand FLOW-30:

- Flow rate: $0 \div 30 \mathrm{~m}^{3} \cdot \mathrm{h}^{-1}$

- Measurements of pressure drop: $0 \div 250 \mathrm{kPa}$

- Heating power: $0 \div 5000 \mathrm{~W}$

- Cooling power: $0 \div 7000 \mathrm{~W}$

- Measurements of vacuum on the end of the channel: $-100 \div 0 \mathrm{kPa}$

- Nominal working fluid temperature: $0-60^{\circ} \mathrm{C}$

Temperature inside of the irradiation device and the water temperature were measured with the k-type thermocouples.

\section{Methodology}

Initially a set of measurements was performed in order to determine the pressure drop characteristics of the irradiation channel with thermostatic rig inside. Linear pressure drop was consistent with the smooth-pipe regime theory, however local pressure drop at the outlet of the channel due to the complexity of the geometry behaves somewhat differently and is slightly higher than in the simple 1-D theory. The channel outlet was printed in 3D and put inside of the measurement stand. This part is presented in Figure 4, as it can be seen, the geometry contains multiple outlets with different diameters, so the pressure drop is a combination of linear and local ones. Pressure drops of the whole outlet part were measured with cylinders of different diameters attached to the outlet, representing the linear part of the ISHTAR irradiation device. The results of the measurements have been presented in Figure 5. Those results, combined with the pressure drop measurements in the linear part, enabled hydraulic calibration of the irradiation channel. They were used to create a mathematical model for calculating the flow in a channel with variable geometry.

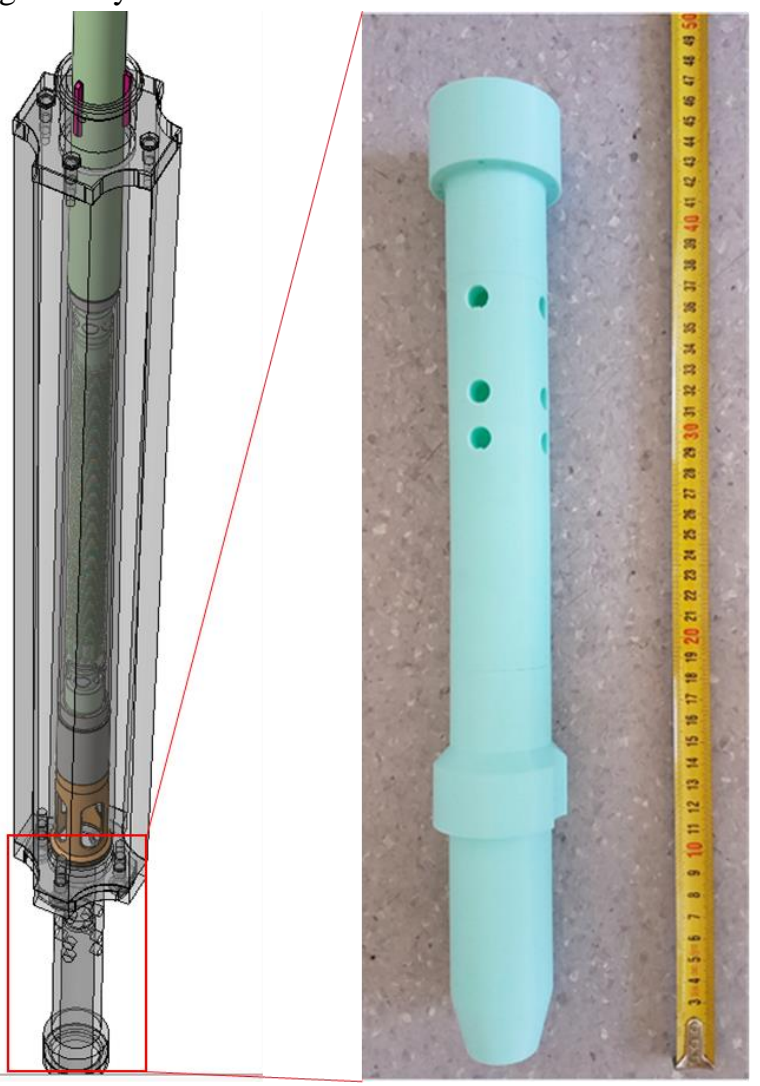

Fig 4: 3D printed hydraulic mock-up of the irradiation channel outlet. Multiple outflows visible. On the left the whole irradiation channel, filled with the ISHTAR device is presented.

In the second part of the measurement, the coolant flow $\left(7 \mathrm{~m}^{3} / \mathrm{h}\right)$ in the channel was set to be consistent with the known pressure drop in the channel $(1.4 \mathrm{kPa})$. ISHTAR irradiation device was placed in the channel and the electric power was gradually increased to $7.2 \mathrm{~kW}$ at which the desired temperature $>1000^{\circ} \mathrm{C}$ was achieved in the sample's region. The time series (temperatures and the electric heaters power) of the experiment are presented in Figure 6. During the 
measurement, thermocouples T1, T2 and T3 were put inside the graphite filler, Twall was welded in a special groove inside the wall.

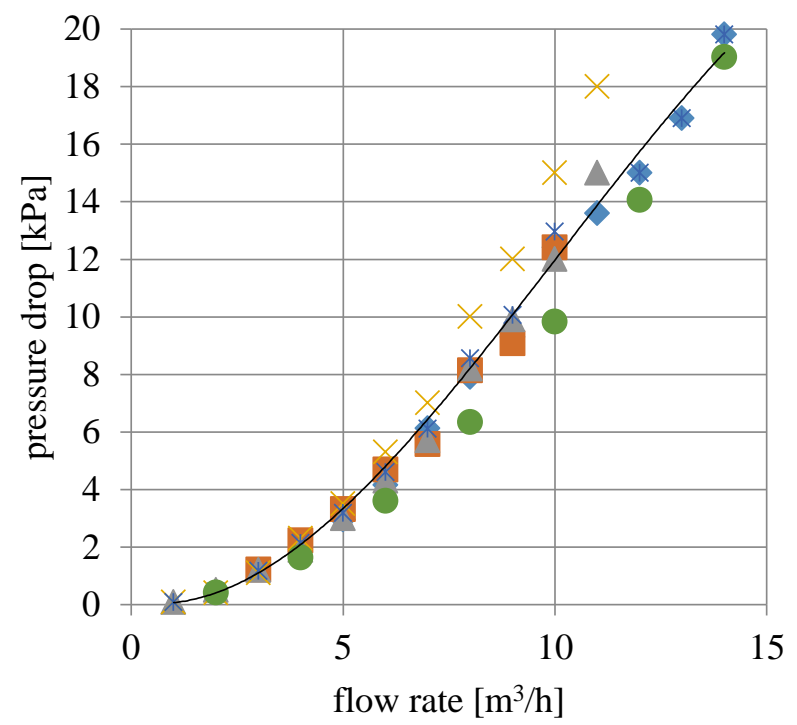

$\diamond$ fi $40 \square$ fi $48.3 \Delta$ fi $0 \times$ fi 0 v2 $*$ mean 0 theory

Fig 5: Pressure drop measurements of the irradiation channel outlet.
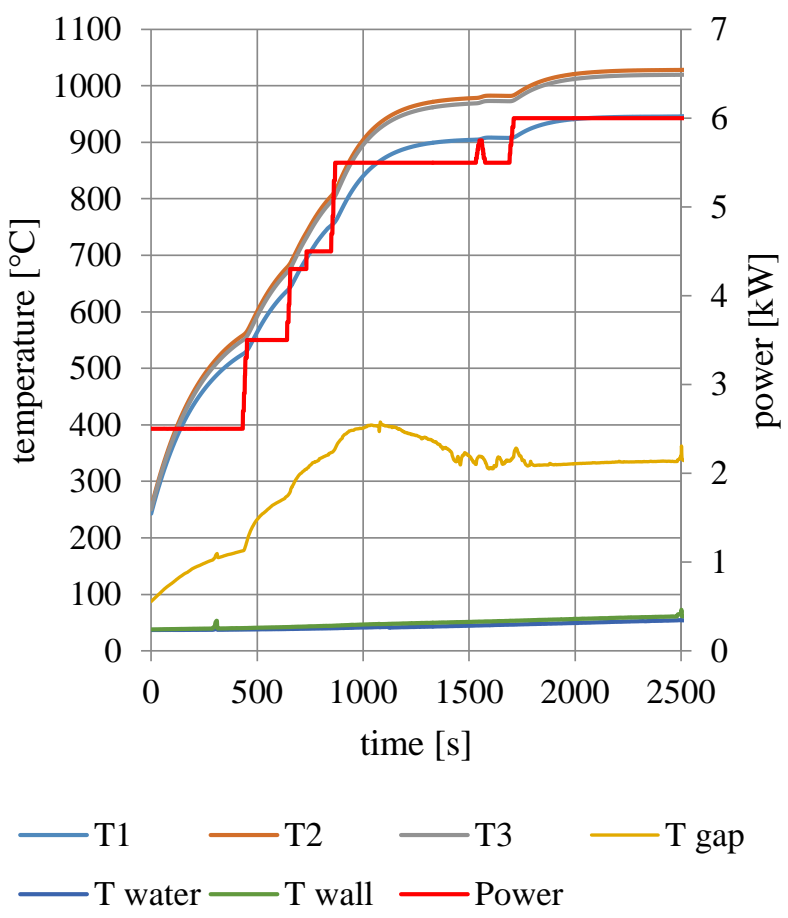

Fig. 6: Time series of the experiment.

T1, T2, T3 - temperatures in the samples region, T gap temperature in the insulation helium gap, $\mathrm{T}$ wall - outer wall temperature, $\mathrm{T}$ water - cooling water temperature, power electric power

\section{RESUlTS DISCUSSION}

When steady state was achieved, comparison of the computations with the measurements results became possible. As it was presented in figures 7 and 8 , both $1 \mathrm{D}$ and 3D calculations proved to be in-line with the measurements. As expected, temperature inside the insulation gap was rising alongside the electrical heaters power increase. Temperature of the helium gap was initially rising and then stabilized at the level $330^{\circ} \mathrm{C}$, probably due to the stabilization of the natural circulation cell within the gas. Heat transfer coefficient was consistent with the theoretical one, calculated from the pressure drop measurements with Gnielinski formula [5] .

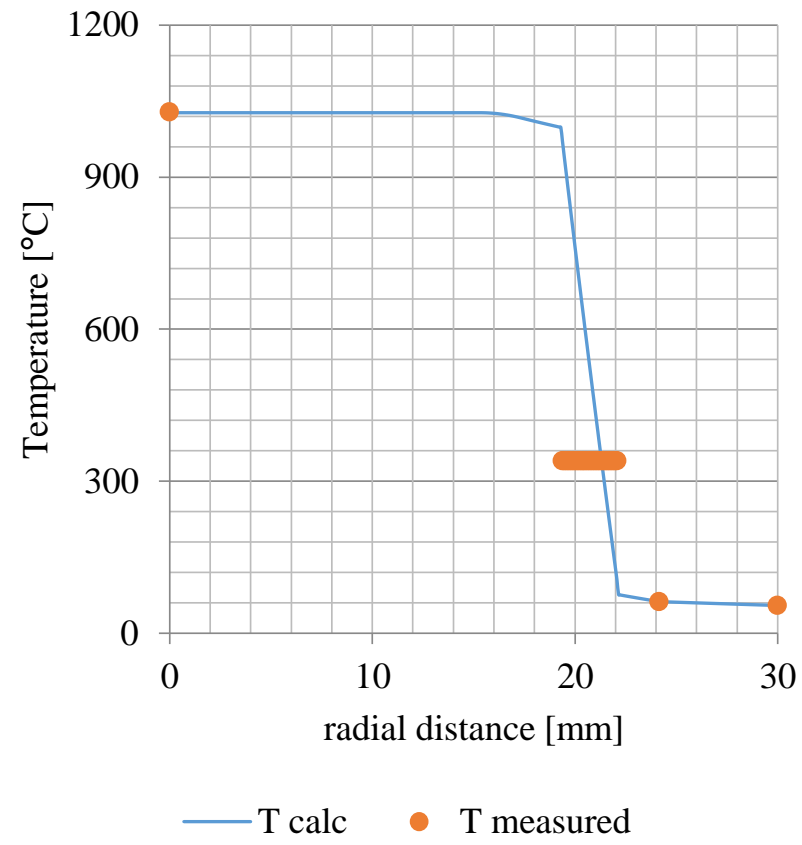

Fig. 7: 1D calculation comparison with temperature measurements. One of the measurement points in the gas gap not well defined.

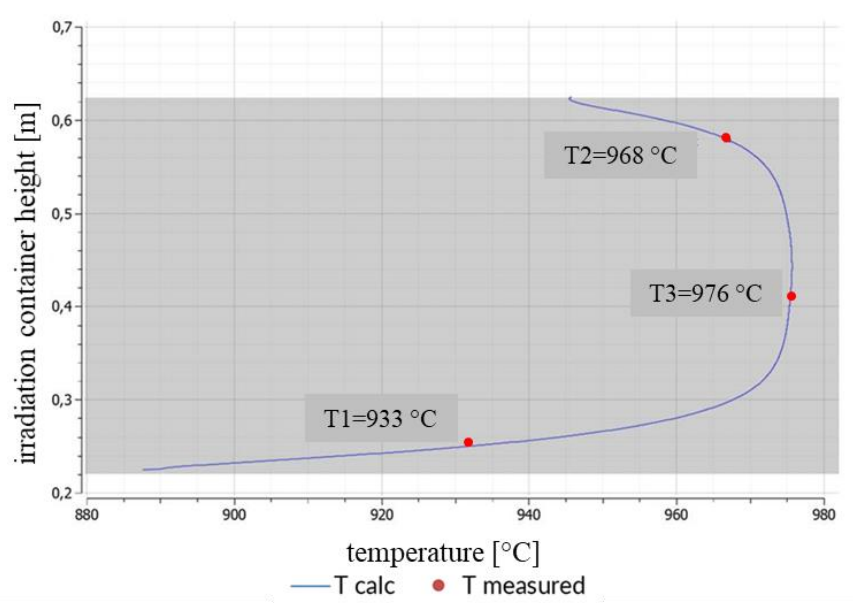

Fig. 8: 3D calculation comparison with temperature measurements 


\section{CONCLUSIONS}

Measurements of the pressure drop in the irradiation channel filled with the thermostatic device were performed., followed by thermal measurements of the temperature field inside and outside the ISHTAR capsule. The temperature measurements results proved the adequacy of the computational methods and the design. ISHTAR thermostatic irradiation device is able to achieve desired parameters, that is, temperature $>1000^{\circ} \mathrm{C}$. The ISHTAR device will be tested inside the core of the MARIA reactor in the fourth quarter of 2021.

\section{ACKNOWLEDGMENT}

This work was supported by the National Centre for Research and Development (NCBR) as a part of the GOSPOSTRATEG-HTR programme.

\section{REFERENCES}

[1] Prokopowicz, R., Pytel, K. (2016). Determination of nuclear fuel burnup axial profile by neutron emission measurement. Nuclear Instruments and Methods in Physics Research Section A: Accelerators, Spectrometers, Detectors and Associated Equipment, 838, 18-23. DOI:

10.1016/j.nima.2016.09.021

[2] https://www.gov.pl/web/klimat/realizacja-prac-projektowych-reaktorahtgr--umowa-podpisanaProgram polskiej energetyki jądrowej

[3] Talarowska A., Lipka M., Wojtania G.,(2021), Preliminary

computational and experimental design studies of the ISHTAR thermostatic rig for the High-Temperature Reactors materials irradiation., Nukleonika, (Revieved)

[4] Official Gazette of the Government of the Republic of Poland, M.P. poz. 946, 6.10.2020. Polish Nuclear Power Programme

[5] Y.A. Cengel, "Internal Forced Convection", in Heat Transfer: A Practical Approach $2^{\text {nd }}$ ed. USA: McGraw-Hill, 2002. Pp 419-458 